\title{
Evaluation of Three Models of Follow-up of Patients with Cervical Cytological Abnormalities in a Peruvian's Largest Teaching Women's Hospital
}

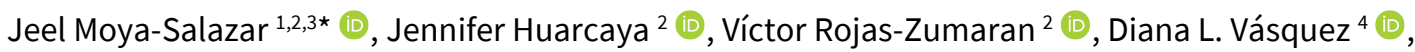 \\ Karina Chicoma-Flores ${ }^{3}$ (D) , Hans Contreras-Pulache ${ }^{1,5 * *}$ (1)
}

\author{
${ }^{1}$ School of Medicine, Faculties of Health Science, Universidad Privada Norbert Wiener, Lima, PERU \\ ${ }^{2}$ Department of Pathology, Hospital Nacional Docente Madre Niño San Bartolomé, Lima, PERU \\ ${ }^{3}$ Oncology Unit, NESH Hubbs, Lima, PERU \\ ${ }^{4}$ Department of Pathology, Instituto Nacional de Enfermedades Neoplásicas, Lima, PERU \\ ${ }^{5}$ South America Center for Education and Research in Public Health, Universidad Norbert Wiener, Lima, PERU \\ *Corresponding Author: jeel.moya@gmail.com \\ **Corresponding Author: hans.contreras@uwiener.edu.pe
}

Citation: Moya-Salazar J, Huarcaya J, Rojas-Zumaran V, Vásquez DL, Chicoma-Flores K, Contreras-Pulache H. Evaluation of Three Models of Follow-up of Patients with Cervical Cytological Abnormalities in a Peruvian's Largest Teaching Women's Hospital. Electron J Gen Med. 2022;19(2):em347. https://doi.org/10.29333/ejgm/11546

\section{ARTICLE INFO}

Received: 6 Dec. 2021

Accepted: 2 Jan. 2022

\begin{abstract}
Introduction: The follow-up of squamous intraepithelial lesions (SIL) allows us to understand their progression and regression, however squamous cell atypia (ASC) can generate confusing follow-up results. We aimed to describe the evolution of ASC and SIL during cyto-histopathological follow-up in a tertiary-care hospital.

Materials and methods: we conducted a retrospective study during 2016 in 156 Papanicolaou test (PAP) results under three models: 1) with $\geq 1$ PAP and biopsies, 2) 1 PAP followed by $\geq 1$ biopsy, and 3) $\geq 1$ PAP and a confirmatory biopsy. Progression was defined as ASCUS to low-grade SIL (LSIL) or higher, and LSIL to high-grade SIL (HSIL) or higher; and regression as HSIL to LSIL or lower; and LSIL to ASCUS or lower.

Results: In PAP, 57 (36.5\%) cases were ASC and in histopathology $56(39.9 \%)$ cases of grade 1 cervical intraepithelial neoplasia. Twenty-nine (18.6\%) results were followed: 8 (27.6\%), 17 (58.6\%), and 4 (13.8\%) with models 1,2 , and 3, respectively. The progression of the lesions was reported in $\sim 50 \%$ for models 2 and 3 . ASCUS was the main cytological finding that indicated biopsies, and for all models, the mean progression and regression time was 4 and 3.1 months, respectively.

Conclusions: The follow-up of cytological alterations in three models showed progression of lesions in half of the cases analyzed with a time of four months of evolution; ASCUS was the main finding that indicated histopathological study.
\end{abstract}

Keywords: atypical squamous cells of the cervix, follow-up studies, squamous intraepithelial lesions, cytology, Peru

\section{INTRODUCTION}

In 1928, as part of the Third Breed Improvement Conference, disruptive Papanicolaou staining showing changes in cellular structures and infectious/inflammatory processes was presented for the first time on black and white slides [1]. Since then, the Papanicolaou (PAP) test has been successful in preventing cervical cancer, reducing its immeasurable incidence and mortality rates worldwide, especially in high-income countries that ensured the organized and sustainable implementation of cervical cancer (CC) screening programs [2,3].

This successful goal has been achieved despite the inherent limitations of PAP [4]. These limitations have prevented equivalent reductions in CC in low- and middleincome countries where only small proportions of reductions in cervical cancer rates have been achieved [5]. Limitations in specimen collection, smear fixation, staining, reading, and interpretation of cytological findings are just a few of the interconnected issues that affect test performance. This reluctance to reduce mortality is associated with its low sensitivity, between $50-85 \%$. However, previous studies have shown that diagnostic sensitivity can be improved with repeated testing and can increase diagnostic certainty and agreement between diagnostic categories in cytology and histology [6-9]. This approach to enhancing PAP quality allows for the comparison of cytological and histological data $[10,11]$ Therefore, follow-up can indicate the progression or regression of initial cytological alterations [12].

In the context of assessing the quality of the cytological diagnosis, follow-up allows the progression and regression of squamous intraepithelial lesions (SIL) to be monitored. However, squamous cell atypia (ASC) can generate confusing 
follow-up results as most of these regresses to benignity $[13,14]$. Follow-up of ASC generally results in remission of cervical lesions, which requires needless histological examinations and adds to the cost of their elucidation [10].

In Lima-Peru, there are two national hospitals specialized in mother-child care that have a PAP-based diagnosis and follow-up program for patients with cervical cancer. The Hospital Nacional Madre Niño San Bartolomé (HONADOMANI $\mathrm{SB})$, the largest teaching women's hospital, performs more than 78 thousand PAP tests annually, examining $35 \%$ of the female population of Lima [8], but the proportion of progressive and regressive cytological findings in their subsequent cytology or the analysis of their cervical biopsies has not yet been assessed. Therefore, there is a need for followup studies to estimate subsequent cytological results characterized by previous findings.

In this study, we describe the evolution of ASC and SIL during cyto-histopathological follow-up at HONADOMANI SB during 2016. We describe the follow-up of one continued PAP with biopsies and several continued PAPs with a biopsy.

\section{MATERIALS AND METHODS}

\section{Design and Study Site}

We designed a retrospective analysis during 2016. The goal of this project was to optimize the processing of PAP by using an automated slide staining method. Improvements in the post-analytical step were implemented in 2016 when it started $[7,8]$. The diagnosis of $C C$ is dependent on PAP because molecular testing for the identification of Human Papillomavirus (HPV) has not yet been introduced in the institution. HONADOMANI SB has seven medical technologists and five pathologists who make up the cytology team.

\section{Cytological and Histopathological Results}

All cytological samples were processed on the Leica ST5010 autostainer XL (Leica Biosystems, Germany). As HONADOMANI $S B$ receives a large number of samples from health networks, PAP results were selected only from hospitals that had two continuous tests or if the PAPs then had a histopathological cervical result within three months. The cytological interpretation suggestions of the Bethesda 2014 guidelines were taken into account when reporting findings [15].

The ASC results, including atypical cells of undetermined significance (ASCUS), atypical cells suggestive of high-grade (ASC-H), and atypical glandular cells (AGUS), were included. For SIL or higher categories, low-grade SIL (LSIL), LSIL with changes corresponding to HPV infection, and high-grade SIL (HSIL), squamous carcinomas and adenocarcinomas were considered. All of these data were gathered from the hospital's Cytology Department's clinical-cytological data storage system. The FIGO 2015 nomenclature was used to document cervical abnormalities such as cervical intraepithelial neoplasia grade 1 (CIN 1$)$, grade 2 (CIN 2), and grade 3 (CIN 3), carcinomas, and other tissue findings for histological results [16]. The results were collected from histopathological reports from the Surgical Pathology area of the Anatomical Pathology Department of the hospital. Both results were corroborated by the Hospital Management System (SIGHOS v2.2).

\section{Inclusion of Patients and Variables}

Patients with results of cytological alteration or monitored precancerous lesions were included in the study. Patients who underwent complete excisional surgeries were omitted since this might skew the results of actual precancerous lesion regression or progression [17]. Data included the date and type of diagnosis, the age of the patients, and subsequent test results within three months.

The primary outcomes measured from the PAP results were (1) the expected time-to-progression test showing (a) ASCUS to LSIL or higher; (b) the expected time to progress from LSIL to HSIL or higher; and (2) the time-to-regression test showing (a) HSIL to LSIL or lower; and (b) LSIL to ASCUS or lower. We looked at complementary biopsy findings followed by $>1$ PAP and subsequent PAP results accompanied by one or two biopsies as secondary outcomes. The ASC-H results were analyzed separately, considering their (1) progression from ASC-H to HSIL or higher and (2) regression from HSIL to ASC-H or lower.

\section{Data Analysis}

Data analysis was performed on IBM SPSS v24.0 (Armonk, USA) for Chrome. The Kolmogorov-Smirnov test was initially employed to determine the data's normality. Then, using absolute frequency measures, we performed a descriptive analysis of both cytological and histological data. For each participant, the analysis periods and diagnoses for PAP and histopathology studies were determined. The Hazard ratios, as well as prediction and regression times, were calculated using the Markov model [18]. Analysis of simultaneity of cytology and histology results was determined based on the availability of the paired results based on cervical specimen collection and analysis data, with 0.05 and a $95 \%$ confidence interval (CI) considered significant for all analyses.

\section{Ethical Aspects}

The ethical principles for human-based medical research established in the Declaration of Helsinki have been adhered to in all phases of the study phases [19]. Furthermore, this research has the approval of the Hospital's Ethics and Research Committee (OID-HONADOMANI-SB-N ${ }^{\circ}$ 17013-16).

\section{RESULTS}

In 2016, 10,385 PAP tests were performed and 486 (4.7\%) had any result with cytological alteration, and only 156 (1.5\%) cases had histo-cytopathological paired reports. The mean age of the patients was $41.1 \pm 12.6$ years ( $95 \% \mathrm{Cl} 39.1$ to 43.1 ) with an upper age limit of 80 years.

Table 1. Summary of cytology results from the Hospital Nacional Docente Madre Niño San Bartolomé, 2016

\begin{tabular}{lcc}
\hline Result & $\mathbf{N}$ & $\%$ \\
\hline NLIM & 3 & 1.9 \\
\hline Undetermined & 57 & 36.5 \\
\hline HPV ${ }^{\star \star}$ & 13 & 8.3 \\
\hline LSIL & 24 & 15.4 \\
\hline LSIL + HPV & 10 & 6.4 \\
\hline HSIL & 35 & 22.4 \\
\hline HSIL + HPV & 7 & 4.5 \\
\hline Carcinoma & 7 & 4.5 \\
\hline Total & $\mathbf{1 5 6}$ & $\mathbf{1 0 0}$ \\
\hline${ }^{\star \star}$ Cellular or tissue changes consistent with Human Papillomavirus
\end{tabular}

(HPV) infection 

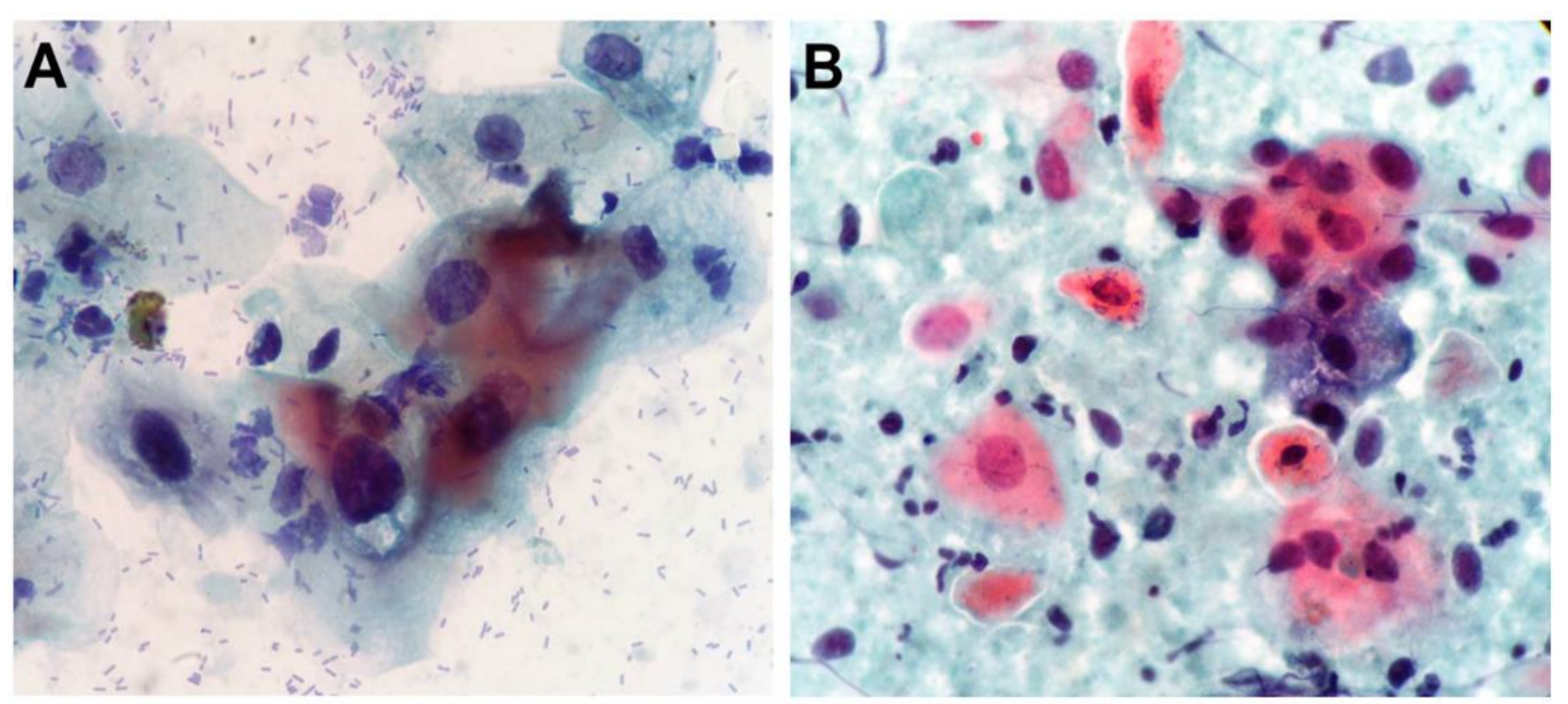

Figure 1. Cytological findings in the follow-up of Peruvian patients during 2016. A: Squamous cell atypia of undetermined significance, with the presence of koilocytes (100X). B: Squamous cell carcinoma (100X)

Table 2. Summary of histopathology results from the Hospital Nacional Docente Madre Niño San Bartolomé, 2016

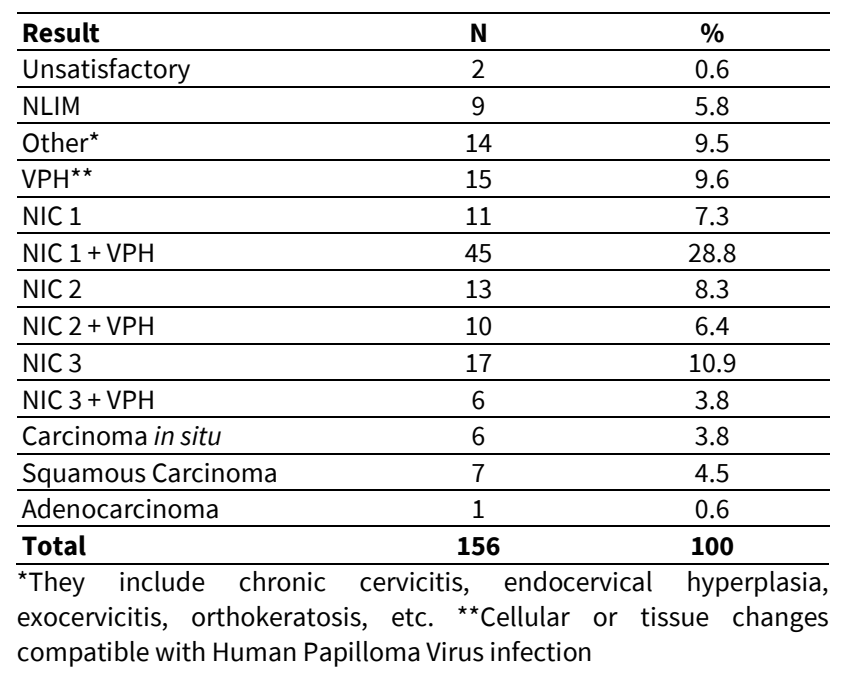

The cytological results are shown in Table 1, where NLMI is negative for epithelial lesion or malignancy, HPV is human papillomavirus, LSIL is low-grade squamous intraepithelial lesions, and HSIL is high-grade squamous intraepithelial lesions. 36.5\% (57 cases) were indeterminate alterations such as ASCUS $22.4 \%$ (35 cases), ASC-H 12.2\% (19 cases), and AGUS $1.9 \%$ ( 3 cases). There were $21.8 \%$ (34 cases) LSIL and $26.9 \%$ (42 cases) HSIL findings. Carcinomas accounted for $4.5 \%$ ( 7 cases) of carcinoma findings. HPV-associated cytological changes were present in $4.5 \%$ ( 7 cases) of HSIL and $6.4 \%$ (10 cases) of LSIL (Figure 1).

Histopathological findings are shown in Table 2, where CIN is 1 cervical intraepithelial neoplasia grade 1, CIN 2 is cervical intraepithelial neoplasia grade 2, and $\mathrm{CIN} 3$ is cervical intraepithelial neoplasia grade 3. HPV koilocytosis was present in the results of $9.6 \%$ (15 cases). The number of findings with CIN1, CIN 2, and CIN 3 were 39.9\% (56 cases) and 14.7\% (23 cases each), respectively. Squamous carcinomas represented $4.5 \%$ ( 7 cases) and only $0.6 \%$ of the cases were cervical adenocarcinoma. HPV-associated tissue changes were present

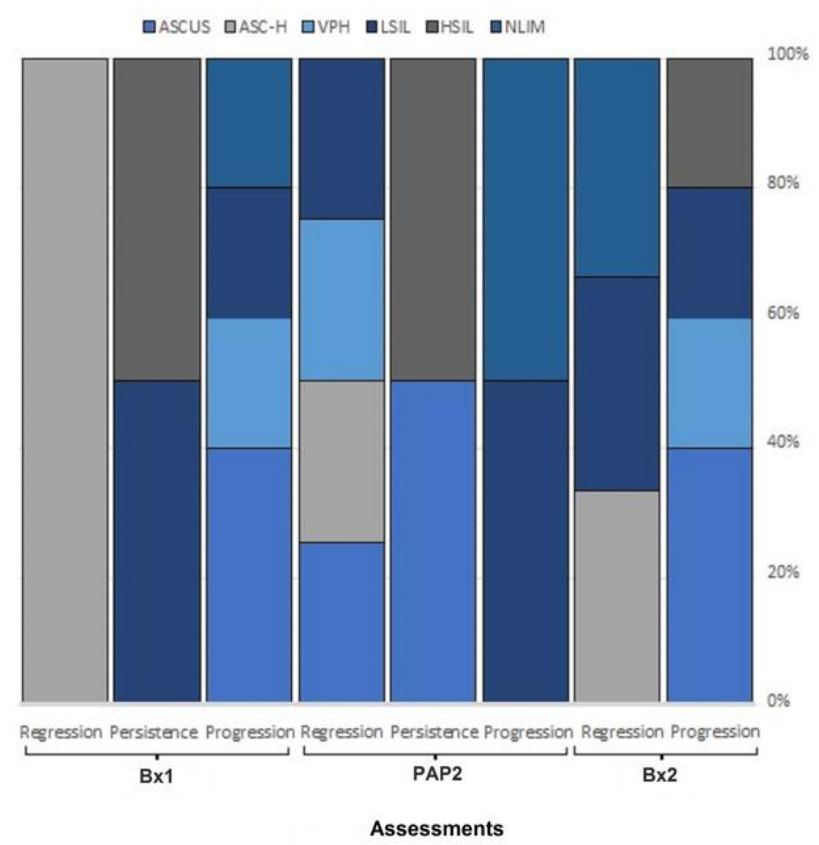

Figure 2. Follow-up model 1 of paired PAP and biopsy results. Cytology result with more than two PAPs and biopsies

in $4.5 \%$ (45 cases) of CIN1, 10 (6.4\%) of CIN2 and 6 (3.8\%) cases of CIN3.

The results of the follow-up and evolution of the tests are shown in Figure 2, Figure 3, and Figure 4, where SCUS is squamous cell atypia of undetermined significance and ASC-H is atypical cells suggestive of high grade or malignancy. Data are in $\%$. Only $18.6 \%(29 / 156)$ of the matched results were followed. Of these, $8(27.6 \%)$ cases had more than two PAPs and biopsies (Figure 2, model 1), 17 (58.6\%) cases had one cytology and more than two biopsies (Figure 3, model 2), and $4(13.8 \%)$ cases had two PAPs and one biopsy (Figure 4, model 3). Although we reported a high proportion of indeterminate and HSIL results in PAP, histological findings had a high proportion of CIN 1. For all models, differences between the evaluation groups were evident $(p<0.05)$. 


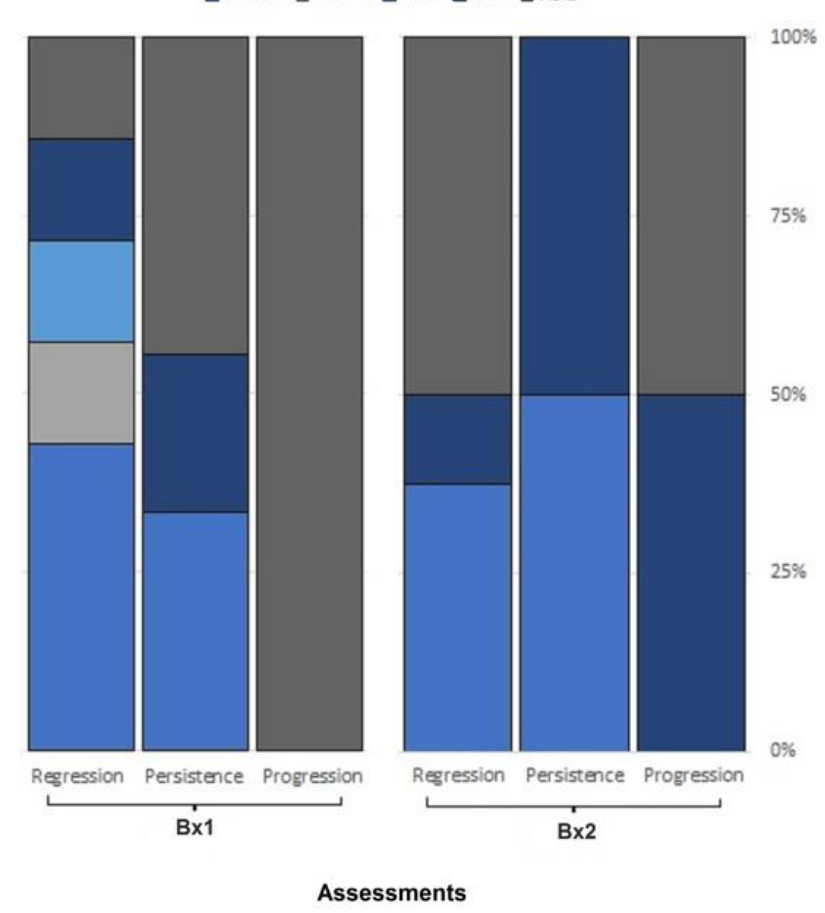

Figure 3. Follow-up model 2 of paired PAP and biopsy results. Cytology result with one PAP and more than one biopsy

For model 1 (as shown in Figure 2), there were more cases of ASCUS and LSIL that required subsequent follow-up, where $62.5 \%(5 / 8)$ had progression at the first biopsy (meantime, 3 months). For the second cytology, there were more cases of regression (time 3.2 months) and for the second biopsy, there were more cases of progression of the alterations (time 2.7 months), both with 5 (62.5\%) cases.

For model 2 (as shown in Figure 3), the initial cytological findings leading to subsequent biopsies were ASCUS and HSIL, both with 6 (35.3\%) cases. Subsequently, the first biopsy had persistence of the lesion for HSIL and LSIL ( $n=3,17.6 \%)$, and for

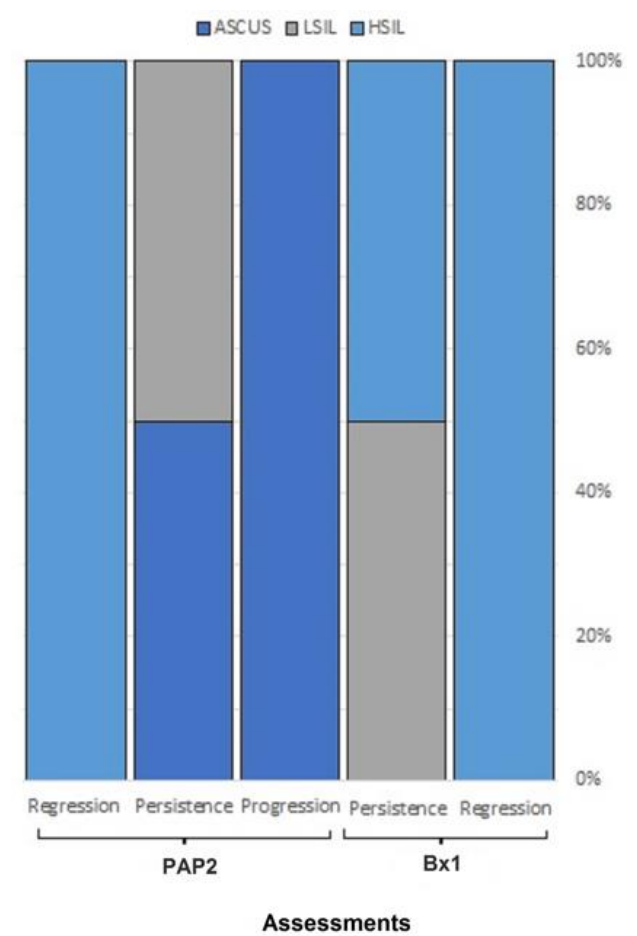

Figure 4. Follow-up model 3 of paired PAP and biopsy results. Cytology result with one PAP and one subsequent biopsy

ASCUS the results corresponded to CIN1. The time to progression and persistence averaged 3 and 1.5 months, respectively. In the second biopsy, progression was evident in $8(47.1 \%)$ cases with a progression time of 6.5 months. In only two $(11.7 \%)$ cases, regression was reported with an average time of 3 months.

In model 3 (as shown in Figure 4), there were cases of persistence of cytological alteration at 3 months, while in the control biopsy 2 (50\%) cases showed progression. The main cytological alterations leading to follow-up and inclusion in the biopsy were HSIL (50\%). 3/4 of the cytological follow-up

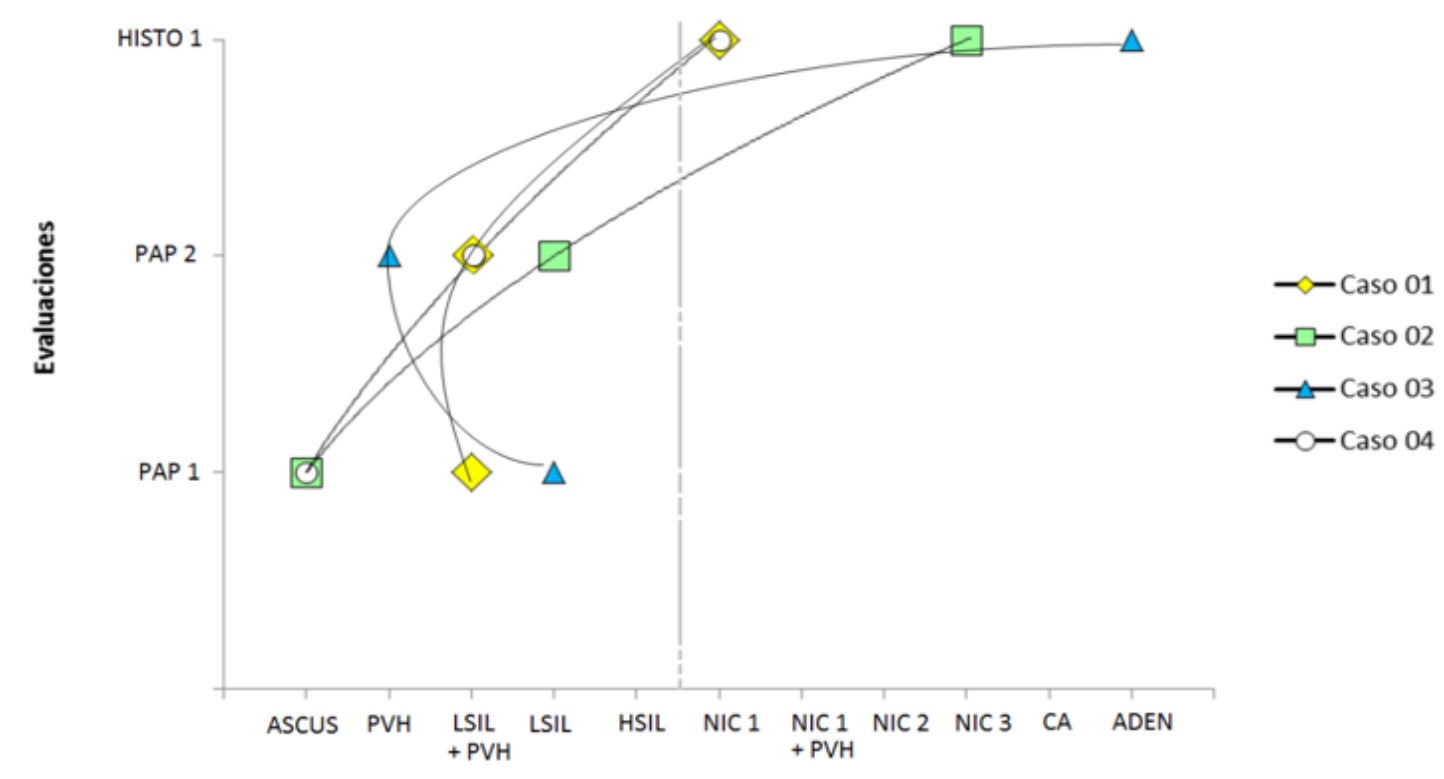

Hallazgos citohistopatológicos

Figure 5. Follow-up of cytological results with two PAPs and later confirmed by histology (biopsy) 
findings confirmed or revealed a large cervical lesion at biopsy in all patients (Figure 5). In Figure 5, CA is squamous carcinoma, ADEN is adenocarcinoma, PAP is Papanicolaou test, and HISTO is histopathological analysis. Only one instance had high-grade lesions at first (HSIL), then regression (NLIM with koilocytosis) at the second cytology and remarkable progress at the final histopathological control (infiltrating adenocarcinoma).

\section{DISCUSSION}

In this follow-up study of cytological alterations, three models were evaluated, which showed the progression of lesions by $\sim 50 \%$ for model 2 (one PAP and $\geq 1$ biopsy) and 3 ( 2 PAPs and 1 biopsy) and a heterogeneous regression and progression pattern for model 1 . ASCUS was also the most common cytological result that required biopsies, and the average time to progression and regression for all models was 4 and 3.1 months, respectively.

Although there have been numerous previous national cohort study follow-ups on lesion of approximately 12 years [14-17], there have also been follow-up studies that have only looked at a limited fraction of accessible cytologies due to a lack of comprehensive data for a proper progression analysis $[9,10]$. Our analyses in a largest tertiary-care women's hospital in Peru have also focused on a group of cases (156/10,385 patients) with follow-up, similar to previous reports in Nepal (75/1,922 patients) and Italy (24/264 patients) $[9,10]$.

A five-year Colombian follow-up study of 2,771 ASCUS results identified $69.8 \%$ and $84.6 \%$ regression and $10.8 \%$ and $6.6 \%$ progression to the first and second cytological control, respectively [12]. Our results are consistent as we had a high proportion of biopsy-confirmed ASCUS progression in 47\% of the cases. Additionally, our ASCUS results, in particular, showed a slow progression to LSIL in subsequent controls; this progression time could be affected by ethnicity, as Hispanic patients have shown a slower progression from ASCUS to LSIL than Asian, African-American and Caucasian patients [17].

However, Hispanics also demonstrated a faster progression rate from LSIL to HSIL compared to all other racial categories. The lowest regression rate from LSIL to ASCUS was also reported for Hispanics [17]. In the Latin American population, a $1 \%$ progression rate for HSIL has been reported [12], with a higher risk of CIN 3 in those over 60 years of age (42.8\%) [20]. As HSIL has a high proportion of CIN 2 and CIN 3 , it is necessary to perform combined tests (including HPV genotyping and co-testing) to increase the possibility of detection in all age groups [21].

On the other hand, another study in China has shown progression to CIN 1 in 16\%, CIN 2 in 19.4\%, and CIN 3+ (or carcinoma in situ) in $11.8 \%$ at 3 -year of histopathological follow-up of ASCUS [20]. Our Model 2 results have allowed the detection of larger lesions in $47 \%$ of cases, in agreement with this previous study. However, in Model 1 we report a different proportion of results with progression (Figure 2). Therefore, although these results have allowed us to identify larger lesions, more prospective-cohort studies with longer follow-up times are required [20].

Exfoliative cytology is subject to a set of interdependent factors that grade its final quality. These factors range from specimen collection to results delivery and sample storage [4-
$8,22,23]$. Additionally, the performance of PAP can vary between populations and its success depends on its organization, and in the same way, PAP represents a sensitive tool for the detection of cervical lesions through follow-up $[24,25]$. It has been shown that sensitivity in the detection of CIN 1 of $93 \%$ and the specificity of $73 \%$ have been detailed, and the sensitivity and specificity of cytology for women with CIN $2+$ were $64 \%$ and $84 \%$, respectively [26]. Although its performance may vary during follow-up, progression (24\%) and regression (31\%) of cervical lesions in women with Human Immunodeficiency Virus infection were identified at two years [27]. Therefore, postpartum follow-up in women with LSIL and HSIL showed persistence in $69 \%$ and $50 \%$ of cases, respectively [28].

According to our findings, the formation of two cervical PAPs allowed the confirmation or discovery of a large cervical lesion in histopathological research, primarily in ASCUS. There are still ambiguous follow-up results for ASCUS and LSIL, where negative cytology has been reported in $64.8 \%$ and $47.8 \%$, respectively [29]. Another study did no found any difference at one-year follow-up between ASCUS and LSIL, with an association of HPV with ASCUS [19]. National and regional follow-up studies of ASCUS are needed including molecular testing and surveillance for the detection of major lesions, as there are differences in performance frequency [30,31].

Of the analyzed models, the most frequent involves the repeated use of PAP as it has an optimal diagnostic yield that improves with repetition [4, 5, 32]. Under this approach (with $\geq 1 \mathrm{PAP}$ ) it has been shown in a 22-year follow-up cohort in Sweden that women with a first cytological diagnosis of ASCUS/LSIL up to 27 years of age can be safely followed with PAP in six months [14]. Follow-up to rule out false-positive results has been estimated at three months, although to correctly demonstrate regression of lesions in ASCUS/LSIL has been estimated at one year of follow-up $[13,20]$. Our results have shown evidence of progression of the lesion with threemonth follow-up and subsequent biopsy-confirmed PAP controls.

This study had the following limitations.

1. Progression, regression, and frequency of cytological alterations can vary between populations according to age group, ethnicity, parity, abortion rate, and incidence of cervical infections [17-20].

2. Follow-up results were estimated in one hospital in Peru, and progression and regression results in other hospitals are needed to understand national differences. It is necessary to carry out extensive studies that include different hospitals in the Andes, jungle, and coast, since Peru is a multicultural country.

In conclusion, in this study, progression was observed in half of the samples in the three models analyzed, with a time of four months of evolution. Furthermore, ASCUS was the main finding, leading to a further histopathological study and the regression time was estimated at three months.

Author contributions: JMS: provided the study concept and design, statistical analysis, data management, and wrote the manuscript. JH: provided the design, data acquisition, formal analysis, and performed data management. VRZ: provided the design, data acquisition, and formal analysis. DLV: provided the design, and data acquisition. HCP: provided the study concept, statistical analysis, data analysis and interpretation, and wrote the article. All authors have sufficiently contributed to the study, and agreed with the results and conclusions. All authors have approved the final version to be published. 
Funding: No funding source is reported for this study.

Acknowledgements: The authors thank the entire team of the Anatomical Pathology Service of the Hospital Nacional Docente Madre Niño San Bartolomé for the facilities provided for the development of the study. The authors also thank the technical team of the NESHHubbs Inc. in Lima for their support in data analysis.

Declaration of interest: No conflict of interest is declared by authors.

\section{REFERENCES}

1. Papanicolaou GN. New cancer diagnosis. In: Proceedings of the 3rd Race Betterment Conference. Battle Creek, Michigan, USA; 1928. p. 528-34.

2. Albrow R, Kitchener H, Gupta N, Desai M. Cervical screening in England: The past, present, and future. Cancer Cytophatol 2012;120(2):87-96. https://doi.org/10.1002/ cncy.20203 PMid:22367883

3. Lăără E, Day NE, Hakama M. Trends in mortality from cervical cancer in the Nordic countries: Association with organized screening programmes. Lancet 1987;1(8544):1247-9. https://doi.org/10.1016/s0140-6736 (87) $92695-x$

4. Koss LG. The Papanicolaou test for cervical cancer detection. A triumph and a tragedy. JAMA 1989;261(5):73743. https://doi.org/10.1001/jama.261.5.737 PMid:2642983

5. Alonso de Ruiz P, Lazcano PE, Hernández AM. Cáncer cervicouterino. Diagnóstico, prevención y control [Cervical cancer. Diagnosis, prevention and control]. Buenos Aires: Editorial Medica Panamericana; 2000.

6. Branca M, Longatto-Filho A. Recommendations on quality control and quality assurance in cervical cytology. Acta Cytol 2015;59(5):361-9. https://doi.org/10.1159/000441515 PMid:26569109

7. Moya-Salazar J, Rojas-Zumaran V, Torres-Martínez R, Rosas-Vargas L. Calidad de los extendidos cervicouterinos dentro de la coloración de Papanicolaou para el cribado de cáncer cervical en Lima, Perú [Quality of cervical smears within Papanicolaou staining for cervical cancer screening in Lima, Peru]. Rev Esp Patol 2016;49(1):7-18. https://doi.org/10.1016/j.patol.2015.12.001

8. Moya-Salazar J, Rojas-Zumaran V. Control de calidad postanalítico en citología exfoliativa cervical en Lima, Perú [Post-analytical quality control in cervical exfoliative cytology in Lima, Peru]. Rev Esp Patol 2017;50(4):207-17. https://doi.org/10.1016/j.patol.2017.05.002

9. Dhakal R, Makaju R, Sharma S, Bhandari S, Shrestha S, Bastakoti R. Correlation of cervical pap smear with biopsy in the lesion of cervix. Kathmandu Univ Med J 2016;55(3):254-7.

10. Chen E, Tran A, Raho C, Birch CM, Crum CP, Hirsch MS. Histological 'progression' from low (LSIL) to high (HSIL) squamous intraepithelial lesion is an uncommon event and an indication for quality assurance review. Mod Pathol 2018;23:1045-51. https://doi.org/10.1038/modpathol.2010. 85 PMid:20473279

11. Crothers BA. Cytologic-histologic correlation: Where are we now, and where are we going? Cancer Cytophatol 2018;126(5):301-8. https://doi.org/10.1002/cncy.21991 PMid:29579352
12. Agudelo-Hincapié KJ, García-Carvajal DL, Cardona-Arias JA, Valencia-Arredondo M. Seguimiento de pacientes con atipia de células escamosas de significado indeterminado (ASCUS) en un servicio citológico de Medellín (Colombia), 2011-2015 [Follow-up of patients with squamous cell atypia of undetermined significance (ASCUS) in a cytology service in Medellín (Colombia), 2011-2015]. Med Lab 2016;22(910):447-58. https://doi.org/10.36384/01232576.93

13. Ciavattini A, Clemente N, Tsiroglou D, et al. Follow up in women with biopsy diagnosis of cervical low-grade squamous intraepithelial lesion (LSIL): How long should it be? Arch Gynecol Obstet 2017;295:997-1003. https://doi.org/10.1007/s00404-017-4335-7 PMid:28255767

14. Sundström K, Lu D, Elfström KM, et al. Follow-up of women with cervical cytological abnormalities showing atypical squamous cells of undetermined significance or low-grade squamous intraepithelial lesion: A nationwide cohort study. Am J Obstet Gynecol 2017;216(1):48.e1-48.e15. https://doi.org/10.1016/j.ajog.2016.07.042 PMid:27457115

15. Nayar R, Wilbur DC. The bethesda system for reporting cervical cytology. Definitions, criteria, and explanatory notes. 3th Ed. Switzerland: Springer; 2015. https://doi.org/ 10.1007/978-3-319-11074-5

16. Bhatla N, Aoki D, Sharma DN, Sankaranarayanan R. Cancer of the cervix uteri. Int J Gyn Obst 2018;143(S2):22-36. https://doi.org/10.1002/ijgo.12611 PMid:30306584

17. Martingano D, Renson A, Martingano AJ, Martingano FX. Variations in progression and regression of precancerous lesions of the uterine cervix on ctology testing among women of different races. J Am Osteopath Assoc 2018;118(1):8-18. https://doi.org/10.7556/jaoa.2018.003 PMid:29309102

18. Andersen PK, Keiding N. Multi-state models for event history analysis. Stat Methods Med Res 2002;11(2):91-115. https://doi.org/10.1191/0962280202SM276ra PMid: 12040698

19. World Medical Association. WMA declaration of HelsinkiEthical principles for medical research involving human subjects. Fortaleza: 64th WMA General Assembly; 2013.

20. Wang YY, Kong LH, Liu Y, et al. Retrospective analysis of cervical cancer and precancerous lesions in patients with atypical squamous cells of undetermined significance in China. Medicine 2019;98:49(e18239). https://doi.org/ 10.1097/MD.0000000000018239 PMid:31804350 PMCid: PMC6919524

21. Luo HX, Du H, Liu ZH, Zhang L, Wang C, Wu RF. [Evaluation of CIN2+ /CIN3+ risk of different HPV subtypes infection combined with abnormal cytology status]. Zhonghua Zhong Liu Za Zhi 2018;40(3):232-8. https://doi.org/10.3760/ cma.j.issn.0253-3766.2018.03.015

22. Vrbin CM, Grzybicki DM, Zaleski MS, Raab SS. Variability in cytologic-histologic correlation practices and implications for patient safety. Arch Pathol Lab Med 2005;129:893-8. https://doi.org/10.5858/2005-129-893-VICCPA PMid: 15974812

23. Austin RM, Zhao C. Is $58 \%$ sensitivity for detection of cervical intraepithelial neoplasia 3 and invasive cervical cancer optimal for cervical screening? Cytojournal 2014;11:14. https://doi.org/10.4103/1742-6413.132997 PMid:24987445 PMCid:PMC4058958

24. National Cancer Institute. Cervical Cancer Screening (PDQ ${ }^{\circledR}$. Health Professional Version. Bethesda: PDQ Screening and Prevention Editorial Board; NCl; 2020. 
25. Li K, Yin R. Repeat cytology and human papillomavirus screening strategies in detecting preinvasive cervical lesions. Medicine 2015;94(5):1-5. https://doi.org/10.1097/ MD.0000000000000435 PMid:25654377 PMCid: PMC4602724

26. Cobucci RNO, Maisonnette MJA, Macêdo EJS, et al. Pap test accuracy and severity of squamous intraepithelial lesion. Ind J Cancer 2016;53(1):74-6. https://doi.org/10.4103/0019509X.180825 PMid:27146747

27. Lofgren SM, Tadros T, Herring-Bailey G, et al. Progression and regression of cervical pap test Lesions in an Urban AIDS clinic in the combined antiretroviral therapy era: A longitudinal, retrospective study. AIDS Res Hum Retroviruses 2015;31(5):508-13. https://doi.org/10.1089/ aid.2014.0254 PMid:25693769 PMCid:PMC4516909

28. Bakari F, Abdul MA, Ahmed SA. The prevalence and course of preinvasive cervical lesions during pregnancy in a northern Nigerian teaching hospital. Ann Afr Med 2017; 16(2):74-80. https://doi.org/10.4103/aam.aam_35_16 PMid:28469121 PMCid:PMC5452714

29. Lopez-Olmos L. Atipias de células escamosas de significado incierto (ASCUS) y lesión escamosa intraepitelial de bajo grado (LSIL). Control citológico evolutivo a 3 meses. Resultados [Squamous cell atypia of uncertain significance (ASCUS) and low-grade squamous intraepithelial lesion (LSIL). 3-month evolutionary cytological control. Results]. Clin Inv Gin Obst 2019;46(3):107-14. https://doi.org/ 10.1016/j.gine.2019.02.001
30. Kim YS, Lee S, Zong N, Kahng J. Clinical progress of human papillomavirus genotypes and their persistent infection in subjects with atypical squamous cells of undetermined significance cytology: Statistical and latent Dirichlet allocation analysis. Exp Ther Med 2017;13(6):3032-8. https://doi.org/10.3892/etm.2017.4295 PMid:28587376 PMCid:PMC5450758

31. Kyrgiou M, Kalliala IEJ, Mitra A, et al. Immediate referral to colposcopy versus cytological surveillance for minor cervical cytological abnormalities in the absence of HPV test. Cochrane Database Syst Rev 2017;1(1):CD009836. https://doi.org/10.1002/14651858.CD009836.pub2 PMid: 28125861 PMCid:PMC646431

32. Moya-Salazar J, Rojas-Zumaran V. Tendencias en la investigación del virus de papiloma humano en Latinoamérica y en los en los países de altos ingresos [Trends in human papillomavirus research in Latin America and in high-income countries]. Rev Col Obst Gin 2017;68(3):128-34. https://doi.org/10.18597/rcog.2679 